\title{
Brooke Modified Medical Research Council Manual Muscle Test Score, Extension
}

National Cancer Institute

\section{Source}

National Cancer Institute. Brooke Modified Medical Research Council Manual Muscle

Test Score, Extension. NCI Thesaurus. Code C139220.

The numerical value that represents the result of a clinical assessment of muscle strength and function during extension that is based on the Brooke Modified Medical Research Council Manual Muscle Test. (Brooke MH, Griggs RC, Mendell JR, Fenichel GM, et al. Clinical trial in Duchenne dystrophy. I. The design of the protocol. Muscle Nerve. 1981 May-Jun;4(3):186-97. doi:10.1002/mus.880040304). 